Original Research Article

\title{
Evaluation of capsule labelling for its wall contents as gelatin or non gelatin
}

\author{
Shallini Gupta ${ }^{1 *}$, Kanika Khajuria ${ }^{1}$, Niraj Kumar ${ }^{2}$, Vijay Khajuria ${ }^{1}$
}

${ }^{1}$ Department of Pharmacology, Government Medical College, Jammu, J\&K, India

${ }^{2}$ Department of Pediatrics, Sub District Hospital, Akhnoor, Jammu, J\&K, India

Received: 07 May 2018

Revised: 24 May 2018

Accepted: 30 May 2018

*Correspondence to:

Dr. Shallini Gupta,

Email: shallinirajkdr@ gmail.com

Copyright: (C) the author(s), publisher and licensee Medip Academy. This is an openaccess article distributed under the terms of the Creative Commons Attribution NonCommercial License, which permits unrestricted noncommercial use, distribution, and reproduction in any medium, provided the original work is properly cited.

\begin{abstract}
Background: Capsules are the most commonly used solid drug dosage form and are made up of gelatin or non gelatin. Currently the gelatin based capsules drug formulations are more used. However, current issue of vegetarian and non vegetarian capsules has come up due to recent Indian government initiative to promote vegetarian capsules.

Methods: There were 100 capsule dosage forms were examined for the gelatin or HPMC wall contents and nature of medicine contained in capsules, whether ayurvedic or allopathic.

Results: Out of 100 capsules studied 55 had gelatin wall base while 25 had HPMC and 20 capsule labels did not mention the nature of capsule wall constituent. Out of 55 gelatin capsules 30 were of allopathic while 25 capsules were of ayurvedic medicines. Among HPMC, 15 were ayurvedic while 10 allopathic. 20 capsules had no mention of its constituent and among these non labelled capsule formulations had 11 from ayurvedic and 9 from allopathic medicines.

Conclusions: The current study revealed that gelatin capsules forms bulk in Indian market. Even the gelatin capsules contained ayurvedic medicines while $10 \%$ of HPMC capsules contained allopathic medicines. Non labelled capsules formed $20 \%$ of total capsules. These findings suggest wider scope for promotion of HPMC based capsules.
\end{abstract}

Keywords: Capsule dosage form, Gelatin, HPMC, Non veg capsules, Vegetarian capsules

\section{INTRODUCTION}

Capsules are preferred route of drug delivery of solid oral dosage form as it allows flexibility of formulations. Capsules have advantage over tablets as it protects sensitive ingredients, decrease GIT irritation, tasteless, odourless, easy to swallow, with no extra added ingredients like binders and oil and fat-soluble matter can be taken in capsules. Capsules are mostly made of gelatin derived from animal sources such as bones, skin and hair of cattle and pigs. Whereas, capsules made of hydroxy propyl methyl cellulose (HPMC) commonly known as hypromellose are derived from plant sources and are used in vegetarian capsules, though pullulan and starch may also be used in place of HPMC. ${ }^{1}$ Moisture range above or below $12 \%-16 \%$ can be detrimental to gelatin capsule shell. If the moisture decreases capsule shell become brittle and prone to break while if it is above the range, then shell becomes sticky. ${ }^{2}$ HPMC has lower moisture content and is considered safe over gelatin and have an advantage that they are even suitable for moisture sensitive hygroscopic and liquid formulations where gelatin capsules are not recommended. HPMC shell is polar and hygroscopic solvents in the fill formulations are less likely to migrate to capsule shell or interact with shell material. Absence of crosslinking is further an advantage of HPMC capsules. However higher oxygen permeability due to 
looseness in HPMC capsule shell structure can limit its use in oxygen sensitive compounds. They are also used as coating polymer bioadhesive, thickening agent for sustained release and even to enhance drug solubility. ${ }^{3}$

Recent Government initiative to promote non gelatin capsules has led to debate on non vegetarian versus vegetarian capsules. ${ }^{4}$ Promotion of HPMC capsules keeping in view the religious sentiments is based on the fact that there are millions of vegetarians in India. However, drug technical advisory board expert panel(DTAB) appointed to examine this issue came with conclusion that medicines were meant to save lives and therefore making issue of vegetarian vs non vegetarian is non desirable. ${ }^{5}$

But besides the religious issue the most vital drawback with gelatin capsules is the fear of transmission of spongioform encephalopathy commonly known as mad cow disease from the animal derived capsules. ${ }^{6}$ US FDA alarmed with this directed pharmaceutical industry to ensure that material used in capsule shell should not be from bovine spongioform encephalopathy endemic infected countries. ${ }^{7}$

In our country where type of food consumed vary due to religion, beliefs and food habits, so labelling of capsules assumes importance. Though the usual displaying of circle filled with brown colour denoting non vegetarian or green for vegetarian ingredients has not been allowed by Supreme court of India. ${ }^{8}$ Therefore it was thought of interest to evaluate labels for displaying gelatin or non gelatin capsule wall content to have insight into this issue. The aim of current trial was to study the label of capsule dosage form for identification of its shell contents as gelatin or HPMC.

\section{METHODS}

Labels of different capsules dosage forms were studied for its shell contents by visiting different chemists / allopathic drug stores and ayurvedic drug stores.

\section{Inclusion criteria}

- Capsules containing solid drug product

\section{Exclusion criteria}

- $\quad$ Sustained release capsules

- Tablets

- Other solid or liquid dosage forms of drugs

Capsule cartons having proper labels were randomly selected. The capsule containing cartons were first photographed and afterwards the labels of capsule were examined for its shell contents like gelatin or non gelatin, nature of medicine whether ayurvedic or allopathic and manufacturing pharmaceutical company.

The capsule cartons whose label did not depict the shell content as gelatin or non gelatin(HPMC)were also included for the analysis in the study. Brown colour circle denoting non vegetarian and green circle for vegetarian ingredients was not considered.

The nature of the active drug product enclosed in capsule whether of non vegetarian origin or not was also not taken into account. Even the cost comparison between gelatin and non gelatin base capsule was not done. Prior to start of the study, Institutional Ethics Committee(IEC) approval was taken.

Table 1: Nature of capsule wall contents as gelatin or non gelatin $(n=100)$, number, percentage, nature of medicine and manufacturing company (multinational/local).

\begin{tabular}{|lllllll|}
\hline Capsule wall contents & Number & Percentage & Ayurvedic & Allopathic & \multicolumn{2}{l|}{ Manufacturer } \\
\hline Gelatin & 55 & 55 & 25 & 30 & 44 & 11 \\
\hline HPMC & 25 & 25 & 15 & 10 & 24 & 01 \\
\hline Not labelled & 20 & 20 & 9 & 11 & 12 & 08 \\
\hline
\end{tabular}

In all one hundred labels of different capsules were examined. The nature of shell content, drug contained in capsule like allopathic or ayurvedic, manufacturing pharmaceutical company whether local or multinational were recorded and are presented in table form as number and percentage (Table 1).

\section{RESULTS}

Total of 100 capsules were selected. The cartons of capsules were analysed for brand name, shell wall content whether gelatin or non gelatin, allopathic or ayurvedic and manufacturing company whether multinational or local . It was found that out of 100 capsules dosage form maximum capsules $55(55 \%)$ had gelatin as capsule shell content.

It was followed by 25 capsules those had Hydroxy propyl methylcellulose (HPMC) as shell content accounting for $25 \%$. Whereas 20 capsules $(20 \%)$ labels did not mention the nature of capsules shell whether gelatine based or non gelatin. 
Among 55 gelatin based capsules 30 capsules had allopathic, while 25 capsules had ayurvedic medicines in them. Whereas in the Hydroxy propyl methylcellulose capsules 15 contained ayurvedic medicines and 10 contained allopathic medicines.

There were 20 non labelled capsules that also formed substantial number had 11 ayurvedic while 9 had allopathic formulations. It was also noted that maximum medicines were of multinational brand (80\%). Among the non labelled medicines 12 were from multinational companies while 8 were of local companies. The results obtained are depicted in Table 1.

\section{DISCUSSION}

Capsules are solid dosage forms in which medicinal and inert ingredients are enclosed in a small shell usually made of gelatin. There are two types of capsules, "hard" and "soft." The hard capsule or "two piece" capsule as it consists of two pieces with shorter piece called the "cap" which fits over the longer piece called the "body", while the soft gelatin capsule is a "one piece" capsule. ${ }^{9}$ Unpleasant drug tastes and odors can be masked by the tasteless gelatin shell besides they are easy to administer, attractive in appearance, shells physiologically inert and easily and quickly digested in the gastrointestinal tract and economical. ${ }^{10}$ Though their major disadvantage is the fear regarding bovine spongioform encephalopathy transmission but high temperature and $\mathrm{pH}$ of the manufacturing process of gelatin capsule lead to nearly no risk of carrying this disease.

In present times people are becoming more conscious for the quality and origin of their food supplements. Vegetarian dietary patterns have been reported to be associated with a number of favourable health outcomes. ${ }^{11}$ While diet high in animal protein derived nutrients can be of interest in etiology of obesity and chronic diseases. ${ }^{12}$ In this backdrop the demand for animal-free or vegetarian supplements is growing.

Hydroxy propyl methyl cellulose (HPMC), starch, hydroxy propyl cellulose (HPC) etc are mainly used as alternatives for gelatin. The vegetarian capsules have advantages over non vegetarian capsule as are free from animal derivatives like pork or beef, easy to swallow, soft, low shell odor and have associated perception of healthier product and do not support bacterial growth. ${ }^{13}$ Keeping in mind the cultural interest, beliefs, taboos and preferences of people the present study was conducted to evaluate the capsules labeling for their vegetarian and non vegetarian shell contents.

In the current study maximum (55\%) of the capsules were gelatin based. It is in accordance with earlier reports where the majority of capsules as high as $98 \%$ were of non vegetarian origin. ${ }^{3} 120$ billion gelatin capsules per year are made in India and while only 2 billion capsules have cellulose shells. ${ }^{14}$
It was interesting to know from the findings of current study that $45 \%$ of gelatin based capsules were used to enclose ayurvedic medicines which are mostly associated with notion that being herbal are non animal products.

Though maximum number of vegetarian capsules contained ayurvedic medication but still $40 \%$ had allopathic medicines. This suggests that there was no rigidity regarding nature of drugs they enclose. The most important point emerging the study was that nearly $20 \%$ of the capsule drug formulations had no mention of its shell contents whether gelatin or non gelatin.

HPMC capsules currently are 4 to 5 times costlier than gelatine capsules. While the gelatine capsules manufacturing is simple and more efficient, the HPMC capsules on the other hand are expensive due to lower production yield and conversion ratio compared to gelatine-based capsules. Also, to make HPMC capsules longer time and extensive technology is required. However, price difference will diminish as more pharmaceutical houses opt for production of HPMC capsules as the demand increases.

The current study highlights the issue of vegetarian vs non vegetarian capsule in present scenario. The dietary sensitivity and patient preference may alter the scene in years to come as pharmaceutical houses are likely to promote vegetarian capsules in future.

\section{CONCLUSION}

The current study revealed variability in labelling that gelatin capsules formed the bulk of capsule dosage formulations in the current study. Interestingly, even the gelatin capsules contained ayurvedic medicines while $10 \%$ of HPMC capsules contained allopathic medicines. Non labeled capsules is a important issue and formed $20 \%$ of total capsules. These observations suggest wider scope for the promotion of HPMC based capsules in future.

Funding: No funding sources

Conflict of interest: None declared

Ethical approval: The study was approved by the Institutional Ethics Committee

\section{REFERENCES}

1. Biyani MK. Choosing Capsules: A Primer.Capsules offer certain benefits over tablets for oral-solid dosage drugs, and several types of capsules are available. Pharmaceutical Technology. 2017;41(10):36-41.

2. Gullapalli RP, Mazzitelli CL. Gelatin and non-gelatin capsule dosage forms. J Pharm Sci. 2017;106:145365.

3. Sheladiya DV, Sodha H, Shah K, Desai T. Vegetable Capsule Shell. International Journal of Pharmaceutical and Chemical Sciences. 2012;1(3):1248-55. 
4. Thacker T. Vegetarian capsules: Panel nixes Maneka Gandhi's proposal to replace gelatin with cellulose. Live Mint, E-Paper, Last Published: Thu, Jan 252018.

5. Minutes of the $76^{\text {th }}$ Meeting of Drugs Technical Advisory Board Held; DGHS, Nirman Bhawan; New Delhi, Jan 31st, 2017. Available at: http://www.cdsco.nic.in/writereaddata/Minutes\%20of \%2076th\%20DTAB\%20on\%2031_01_2017.pdf

[Last accessed on 2018 march 28].

6. WHO. Guidelines on Transmissible Spongiform Encephalopathies in relation to Biological and Pharmaceutical Products. WHO Guidelines on Transmissible Spongiform Encephalopathies in Relation to Biological and Pharmaceutical Products. 2003. Available at: http://www.who.int/biologicals/publications/en/whots e2003.pdf. [Last accessed on 2018 march 28].

7. Commissioner of the Search for FDA Guidance Documents - The Sourcing and Processing of Gelatin to Reduce the Potential Risk Posed by Bovine Spongiform Encephalopathy (BSE) in FDARegulated Products for Human Use. U. S. Food and Drug Administration Home Page. [Last accessed on 2017 Jul 11]. Available at: https://www.fda.gov/RegulatoryInformation/Guidanc es/ucm125182.htm .

8. Indian Soaps and Toiletries Makers vs. Ozair Husain and Ors; 7 March 2013. Available at: https://www.indiankanoon.org/doc/27775458/. [Last accessed on 2018 March 29].
9. Augsburger LA. Hard and soft gelatin capsules in Modern Pharmaceutics GS Banker \& CT Rhodes, Eds., and Marcel Dekker, Inc.: New York, NY; 1995:395-440.

10. Chandrika MV, Krishna MV, Jyothirmayi M. Alternatives for gelatin in the preparation of capsules. Adv J Pharm Life Sci Res. 2016;4(2):33-42.

11. Orlich MJ, Jaceldo-Siegl K, Sabaté J, Fan J, Singh PN, Fraser GE. Patterns of food consumption among vegetarians and non-vegetarians. $\mathrm{Br} \mathrm{J}$ Nutr. 2014;112(10):1644-53.

12. Rizzo NS, Jaceldo-Siegl K, Sabate J, Fraser GE. Nutrient Profiles of Vegetarian and Non Vegetarian Dietary Patterns. J Acad Nutr Diet. 2013;113(12):1610-9. Published online 2013 Aug 27.

13. Al-Tabakha MM. HPMC Capsules: Current Status and Future Prospects. J Pharm Pharmaceut Sci. 2010;13(3):428-42

14. Prakash A, Soni H, Mishra A, Sharma P. Are your capsules vegetarian or nonvegetarian: An ethical and scientific justification. Indian $\mathrm{J}$ Pharmacol. 2017;49(5):401-4.

Cite this article as: Gupta S, Khajuria K, Kumar N, Khajuria V. Evaluation of capsule labelling for its wall contents as gelatin or non gelatin. Int J Basic Clin Pharmacol 2018;7:1387-90. 